\title{
OS NOVOS MOVIMENTOS SOCIAIS: O CASO DO MOVIMENTO ODS SANTA CATARINA
}

\section{THE NEW SOCIAL MOVEMENTS: THE CASE OF THE ODS SANTA CATARINA MOVEMENT}

\section{LOS NUEVOS MOVIMIENTOS SOCIALES: EL CASO DEL MOVIMIENTO ODS SANTA CATARINA}

\author{
Diego Fiel Santos ${ }^{1}$ \\ ORCID: https://orcid.org/0000-0001-9105-866X \\ Regina May de Farias ${ }^{2}$ \\ ORCID: https://orcid.org/0000-0002-9230-5842 \\ Carolina Andion ${ }^{3}$ \\ ORCID: https://orcid.org/0000-0003-4723-3437
}

Submissão:13/11/2019 / Aceito: 21/11/2020 Publicado: 20/01/2021.

\begin{abstract}
Resumo
O presente estudo busca compreender a realidade constitutiva de uma ação coletiva voltada para construção do movimento pelos Objetivos de Desenvolvimento Sustentável (ODS) em Santa Catarina. A investigação se apoia no paradigma dos novos movimentos sociais e se propõe a analisar a composição, a construção daidentidade coletiva e as ações e objetivos do movimento. Consiste num estudo de caso, desenvolvido a partir da realização de observação participante e entrevistas semiestruturadas. O Movimento possui como identidade coletiva a ação voltada para o desenvolvimento sustentável, a partir da transformação cultural da sociedade. O alcance de atuação do movimento é considerado positivo, apesar de ainda ser um desafio atingir a plenitude de mudança cultural e do reforço à solidariedade exigidos para promoção da sustentabilidade na prática..
\end{abstract}

Palavras-chave: novos movimentos sociais. identidade coletiva. desenvolvimento sustentável. ação coletiva. mudança cultural.

\begin{abstract}
The present study seeks to understand the constitutive reality of a collective action: the movement for the Sustainable Development Goals in Santa Catarina. The research is anchored in the paradigm of the new social movements and it proposes to analyze the composition, the collective identity construction and the actions and objectives of the movement. It is a case study, developed from the realization of participant observation and semi-structured interviews. The collective identity of the movement turn around the sustainable development, based on the cultural transformation of society. The scope of action of the movement is considered positive, although it is still a challenge to reach the fullness of cultural change and solidarity to promote sustainability in practice..
\end{abstract}

Keywords: new social movements. collective identity. sustainable development. collective action. cultural change.

\section{Resumen}

El presente estudio busca comprender la realidad constitutiva de una acción colectiva: elmovimiento por los Objetivos de Desarrollo Sostenible en Santa Catarina. La investigación es embazada en el paradigma de los

\footnotetext{
${ }^{1}$ Mestrado em Administração pela Universidade Federal do Rio Grande do Norte (2012). Professor Adjunto no Departamento de Secretariado Executivo na Universidade Federal de Sergipe. Doutorando em Administração pela Universidade Federal de Santa Catarina. E-mail: diegosantos@academico.ufs.br.

${ }^{2}$ Especialização em Consultoria em Gestão Empresarial pela Faculdade Energia de Administração e Negócios (FEAN), Consultora do Instituto Comunitário Grande Florianópolis (ICOM) E-mail: regina.may@ gmail.com. ${ }^{3}$ Pós-doutorado em Economia Social pela Universidade de Valência, Espanha. Doutorado em Ciências Humanas Interdisciplinar pela Universidade Federal de Santa Catarina (UFSC). Docente do Departamento de Administração Pública e do Programa de Pós-Graduação em Administração da Universidade do Estado de Santa Catarina (UDESC). E-mail: andion.esag@gmail.com.
} 
nuevos movimientos sociales y se propone analizar la composición, la construcción del identidad colectiva y las acciones y objetivos del movimiento. Es un estudio de caso, desarrollado a partir de la realización de observación participante y entrevistas semiestructuradas. El Movimiento tiene como identidad colectiva la acción orientada hacia el desarrollo sostenible, a partir de la transformación cultural de la sociedad. El alcance de actuación del movimiento se considera positivo, aunque sigue siendo un desafío alcanzar la plenitud de cambio cultural y de la solidaridad exigidos para la promoción de la sostenibilidad en la práctica. sustentable. acción colectiva. cambio cultural.

\section{INTRODUÇÃO}

Os movimentos sociais podem ser definidos enquanto ações coletivas voltadas para a promoção de mudanças sociais e políticas mais amplas. Estes produzem transformações na sociedade por meio de enfrentamentos ou lutas coletivas em diferentes campos de causa. O movimento social representa, assim, os anseios manifestados pela sociedade em relação a direitos, identidades e conquista de novos espaços e novas formas de existência nas interações sociais. Cada movimento social se caracteriza pelo seu repertório (TARROW, 2009) que configura sua identidade enquanto coletivo. Compreender a prática, a forma e as motivações que definem os movimentos sociais são importantes para entender as ações coletivas e as dinâmicas de transformações promovidas por estas na sociedade.

As ações coletivas promovidas pelos movimentos sociais mostram-se relevantes em inúmeros momentos da história. Na realidade brasileira é perceptível - quando observados os objetivos e temas levantados pelos movimentos sociais ao longo do tempo-, que muitas dessas lutas representam hoje direitos assegurados constitucionalmente. Em sociedades conduzidas por princípios democráticos e republicados é possível constatar que os direitos sociais adquiridos são fruto de reivindicações advindas de movimentos sociais. Considerar a historicidade e a trajetória dos problemas públicos e das ações dos movimentos sociais sobre eles permite enxergar e compreender os impactos das ações coletivas na sociedade (ALONSO, 2009; NUNES, 2014).

Em vários países do mundo, os movimentos sociais estão associados ao surgimento de reivindicações por parte da sociedade voltados à conquista de direitos civis e políticos. Os movimentos sociais originalmente surgem representando ações coletivas que buscam melhorias de condições de trabalho, liberdades individuais e ampliação dos direitos políticos. A busca por estes direitos constitui o escopo dos direitos humanos, que por sua vez assumem uma maior amplitude quando se considera os direitos que são almejados, buscados e conquistados pela sociedade. Os direitos sociais, culturais, econômicos, difusos 
e coletivos representam parte da composição referente aos direitos humanos. Esses direitos são fruto da promoção de distintas ações coletivas que estão associados às identidades coletivas dos denominados novos movimentos sociais (NMS) (LACLAU, 1986; CALHOUN, 1993; ALONSO, 2009; ABERS; BULOW, 2011)

Assim, os NMS representam a manifestação de diferentes direitos humanos, que vão além dos direitos civis e políticos. Diante dessa realidade estabelecida pelos NMS surgem diversas percepções quanto à transformação e à preservação dos direitos humanos. Diante dessa problemática mais ampla, o presente estudo busca compreender a realidade constitutiva de uma ação coletiva voltada para construção de um movimento pelos Objetivos de Desenvolvimento Sustentável (ODS), em Santa Catarina. A partir de uma investigação direcionada pelos matizes do paradigma dos NMS, esta investigação se propõe a analisar a composição, a construção daidentidade coletiva desse novo movimento social, bem como as as ações e objetivos apresentados pelo mesmo e verificar o alcance de sua atuação frente aos objetivos determinados pela ação coletiva.

A escolha do objeto de investigação do estudo foi motivada pelo fato do Movimento ODS Santa Catarina ser constituído a partir de uma ação coletiva em rede para a promoção e preservação de direitos humanos de um novo tipo ligados à sustentabilidade. $\mathrm{O}$ estudo parte do entendimento que esse movimento representa as características presentes pelo paradigma dos NMS ao tratar de temas que estão associados aos "novos direitos humanos", voltados para a temática do desenvolvimento sustentável. Porém, o fato do Movimento ODS Santa Catarina ser alicerçado nas dimensões econômica, social, ambiental e institucional demonstra que essa ação coletiva abrange diferentes temáticas e dimensões interrelacionadas que vão além dos temas abordados pelos movimentos sociais tradicionais.

A escolha dos NMS como lente teórica possibilita um olhar sobre uma perspectiva das contribuições a respeito da temática do desenvolvimento sustentável e das ações que estão sendo promovidas para alcança-lo. Nesse contexto, o estudo ao analisar o caso buscou compreender empiricamente a exposição das características relacionadas ao paradigma teórico dos NMS que podem ser associadas às ações coletivas voltadas ao desenvolvimento sustentável.

Para determinação do escopo teórico foram utilizadas a técnicas de levantamento de documentos sobre o movimento e os objetivos de desenvolvimento sustentável. A partir da análise documental foram concebidas as ações para o desenho das entrevistas 
semiestruturada realizadas com os membros do Movimento ODS Santa Catarina. Através das entrevistas foi possível abordar questões relacionadas à constituição do movimento e fazer associação ao recorte teórico dos NMS. Vale salientar que a pesquisa de abordagem qualitativa possui características de uma pesquisa participante pelo fato de um de seus pesquisadores fazer parte do movimento que é objeto da pesquisa. Por fim, a investigação se refere a um estudo de caso, visto que se buscou explorar em profundidade características específicas de um caso, como forma de realizar uma análise detalhada das informações e dados obtidos a partir do recorte teórico utilizado pelo estudo.

Com vistas a responder os objetivos colocados esse artigo écomposto por essa introdução e mais três seções. A próxima seção discute ao recorte teórico referente ao paradigma dos NMS e a forma de interpretação das ações coletivas por esse paradigma, a partir da década de 1970, cenário no qual se inserem novas reivindicações sociais a partir de distintas identidades coletivas. A terceira seção apresenta a análise investigativa realizada a partir dos métodos e técnicas estabelecidos pela pesquisa para o alcance dos seus objetivos. Para finalizar são feitas considerações sobre a pesquisa realizada frente a problematização da investigação, destacando as contribuições alcançadas e expõe-se as possibilidades de novas pesquisas sobre a temática.

\section{O PARADIGMA DOS NOVOS MOVIMENTOS SOCIAIS}

A proposta dessa seção é expor os pressupostos e características associadas ao paradigma dos NMS no estudo das ações coletivas. Os NMS estão associados à abordagem culturalista-acionalista e segundo Gohn (2006) podem ser agrupados em três correntes: a histórico-política, a psicossocial e a acionalista. Cada uma dessas linhas configuram uma lógica de raciocínio em relação a configuração e constituição dos NMS, apresentando distinções e aproximações em seus trabalhos teóricos. A terminologia 'NMS' é recorrentemente associada aos movimentos sociais que emergem na década de 1970 e representa uma crítica à abordagem clássica marxista (GOHN, 2006).

Diante das premissas constitutivas dos NMS, a autora Gohn (2006) apresenta cinco características gerais básicas: (1) um modelo teórico baseado na cultura; (2) a negação do marxismo como meio para explicação da ação dos indivíduos; (3) a supressão das contradições do capitalismo referente ao sujeito histórico redutor da sociedade; (4) a 
redefinição e centralidade da política na análise; e (5) a análise dos atores sociais a partir do processo de suas ações coletivas e pela identidade coletiva coproduzida. É importante destacar que as características apresentadas por Gohn estão associadas a uma posição axiológica. Nesse sentido é necessário buscar uma leitura dos NMS a partir de atributos que os definem de forma dissociada ao posicionamento da autora, sem desconsiderar a relevância e as contribuições da sua interpretação.

Evidencia-se que os NMS atuam no campo da cultura a partir das expressões de suas práticas, considerando a importância que os indivíduos envolvidos dão a questões como solidariedade, lutas sociais e valores compartilhados. A partir do que os atores produzem pela ação coletiva no ambiente em que estão inseridos é possível constatar a sua lógica de ação e a criação da sua identidade coletiva. No corpo teórico dos NMS a identidade coletiva possui centralidade em suas explicações, "a identidade é parte constitutiva da formação dos movimentos, eles crescem em função da defesa dessa identidade" (GOHN, 2006:124). Para compreender a dinâmica dos NMS torna-se relevante entender a identidade a partir do processo de geração de seu conteúdo como fator que motiva os distintos atores sociais. A real compreensão da identidade coletiva presente no paradigma desses movimentos sociais serve como meio para entender o que existe de "novo" e se contrapõe ao "antigo". Os NMS se propõem à configuração das ações coletivas a partir de uma nova forma de fazer política, numa busca pela neutralização das mazelas que configuram a política "antiga" e principalmente pela politização de novos temas (ALONSO, 2009; NUNES, 2014).

Existe associado aos novos temas de ação coletiva uma reestruturação na prática dos movimentos, onde as transformações em sua estrutura morfológica estão relacionadas à totalidade da sociedade. O novo se configura a partir da consciência que os atores sociais passam a ter sobre o poder das interações e a criação de novas identidades nesse processo de construção social da ação coletiva (COHEN e ARATO, 1994). Os NMS se utilizam da publicização através de atividades de protestos e da mídia para trazer à tona os novos temas com o intuito de que sejam observados favoravelmente pela opinião pública. Utilizam essas ações para pressionar as instituições públicas e possibilitar a transformação dos valores dominantes, de forma que os novos questões e pautas passam a compor a agenda pública e sejam problematizados e implementados pela agenda governamental. 
A pluralidade de ideias e valores constituem as ações coletivas que caracterizam os NMS, de tal forma que, segundo Gohn (2006:126), “os movimentos passam a atuar mais como redes de troca de informações e cooperação em eventos e campanhas”. E diante dessa pluralidade podem emergir conflitos internos e externos no processo de constituição da identidade coletiva. Diante da crescente fragmentação e pluralidade da realidade social, a construção da identidade coletiva representa a busca pela constituição de uma unidade que esteja afastada da crise de credibilidade dos canais convencionais de mobilização. Os NMS representam então a busca pela constituição de uma abordagem mais construtivista que faça emergir e possibilitar delimitação de espaços para os novos temas de interesses coletivos que surgem na sociedade. De acordo com Gohn (2006:129), os NMS são "um diagnóstico das manifestações coletivas contemporâneas que geraram movimentos sociais e a demarcação de suas diferenças em relação ao passado", a autora ainda relata que "estes movimentos, por sua vez, geraram certas mudanças significativas, tanto na sociedade civil como na política".

Os NMS simbolizam, assim, a agregação de representações de expressões culturais que constituem os significados da retratação dos novos temas. Diante de sua flexibilidade e ações fluidas o seu enquadramento se constitui enquanto movimento de representação, muitas vezes se contrapondo ao poder do Estado. A partir da construção de alianças e a formação de redes sociais e culturais, os NMS promovem ações políticas a partir do fazer cotidiano, valorizando a autonomia dos indivíduos e grupos sociais para constituição dos processos interativos. No entanto cabe ressaltar a questão enfatizada por Gohn (2006:139) e que também é uma indagação feita por Cohen e Arato (1994), sobre "como os novos movimentos sociais desenvolveriam uma nova cultura política ou novas identidades"?

Diante desse questionamento, os NMS se debruçam sobre os estímulos sociais para a constituição das ações coletivas. Para Touraine (2001) um movimento social possui como elementos constitutivos o conflito, os atores e o adversário. A partir desses elementos é possível interpretar os movimentos sociais pela ótica de sua identidade, oposição e totalidade, sendo realizada uma análise enfatizando os sistemas macrossociais. A vontade expressa pela ação coletiva constitui o movimento social que revela desejos da sociedade a partir de um conflito para conquista de seu campo cultural. Compreender os movimentos sociais exige uma investigação que esteja voltada para descrição e análise dos modelos 
culturais, das relações e interações que perfazem os atores sociais na sua ação coletiva perante a historicidade (ALONSO, 2009; ABERS; BULOW, 2011; NUNES, 2014).

A partir de um enfoque psicossocial, Melucci (1996) afirma que a análise dos NMS se diferencia dos movimentos sociais anteriores a partir da noção de campo cultural como fator central dos estudos. As práticas sociais que são desenvolvidas pelas interações entre indivíduos ou gruposconfiguram o campo de relacionamentos sociais frente e o sentido construído e compreendido pelos atores diante do tema reivindicado. Compreender essas ações frente às interações estabelecidas por sistemas de ação coletiva são importantes para distinguir os NMS de outras configurações da prática social.

De acordo com Gohn (2006:154), “a análise da ação coletiva pode ser dar em cinco níveis: no que concerne à sua definição, à sua formação na estrutura social, a seus componentes, às formas e aos campos onde ocorre". Para a autora, apoiada em Melucci (1996), destacam-se quatro grupos de sistemas que concentram os elementos da ação coletiva: sistema de recursos da sociedade, o sistema político, o sistema organizacional e o sistema das relações sociais. Para Gohn (2006:158), a identidade coletiva "é construída e negociada por uma ativação de relacionamentos sociais que conectam os membros de um grupo ou movimento". A partir do espaço em que ocorrem as ações, das oportunidades e controvérsias, a identidade coletiva é constituída pela interatividade e compartilhamento em um determinado grupo, em uma construção configurada por um sistema de ação.

\footnotetext{
A identidade coletiva é um processo que envolve três mecanismos para a sua definição/constituição: a definição cognitiva concernente a fins, meios e campo de ação; a rede de relacionamentos ativos entre os atores que interagem, comunicam-se, e influenciam uns aos outros, negociam e tomam decisões; e, finalmente, a identidade coletiva requer um certo grau de investimento emocional, qual os indivíduos sintam-se, ele próprios, partes de uma unidade em comum. (Melucci 1996 apud Gohn, 2006:159)
}

Um fator importante a ser considerado na identidade coletiva está relacionado ao fato de ser inteiramente negociável, pois a ação e participação coletivas são constituídas de significados que não podem ser simplesmente reduzidos a perspectiva do cálculo utilitarista. A identidade coletiva também consiste em um processo de aprendizagem, a partir das interações que viabilizam as ações coletivas dos movimentos. Com base nessas constatações, é possível observar a capacidade de autorreflexão dos atores sociais e perceber a existência de uma identidade comum que possui um caráter público e histórico. 
Os NMS também se caracterizam a partir de fenômenos discursivos e políticos, ou seja, suas ações não são moldadas apenas por condições estruturais ou concepções racionais. Nesse sentido, se configura a importância dos movimentos sociais serem interpretados a partir de conjunturas sociopolíticas. Tal compreensão consiste em estabelecer uma articulação entre os campos político e o sociocultural. Essa investigação pode ser traçada e constituída com os procedimentos da análise dialética, com o sentido de observar as relações sociais a partir de suas transformações e as necessidades materiais e simbólicas presentes na sociedade. De acordo com Gohn (2006:165), os NMS se constituem pelo fato que "as demandas e reivindicações não são apenas dos ativistas, mas compartilhadas por uma ampla comunidade de pessoas, competentes e bem informadas" que podem ou não estar envolvidas em movimentos políticos. Os NMS possuem um campo de ação em um espaço de política não-institucional, sendo resultado de uma ação coletiva que reivindica uma categoria intermediária. Diante de suas limitações buscam formas alternativas de reivindicação para valores básicos que são defendidos e associados a questões que configuram sua identidade. Os NMS buscam então estabelecer alianças que possibilitem o alcance de suas reivindicações.

Diante da compreensão aqui colocada dos NMS, suas características e forma de análise, adentramos na próxima seção no estudo de caso do Movimento ODS Santa Catarina..

\section{AnÁlise do Movimento ODS SAnTa Catarina}

Esta seção corresponde aos resultados obtidos com os levantamentos documentais, registros de informações obtidas pelas entrevistas semiestruturadas com pessoas que atuam no Movimento ODS Santa Catarina e as percepções da observação participante. Os dados levantados foram analisados a partir da teoria dos NMS, de forma a compreender a constituição do movimento social a partir de sua configuração de ação coletiva e as práticas desenvolvidas. Dessa forma, foi possível observar a trajetória histórica constitutiva e compreender as configurações e concepções que estão associadas ao Movimento ODS Santa Catarina enquanto movimento social. Sendo observados os valores, formas e normas que constituem a ação coletiva e influenciam o comportamento dos atores sociais envolvidos no movimento social. 
A partir dos relatos é possível caracterizar que o surgimento do movimento social teve como marco o interesse de pessoas e organizações em relação à temática da responsabilidade social no estado de Santa Catarina. Os membros que estavam fazendo parte da composição inicial do movimento atuavam em diferentes áreas e organizações que possuíam um interesse em discutir a questão da responsabilidade socioambiental corporativa.. Essa emergência é descrita por Melluci (1996) para quem os NMS se constituem a partir de mobilizações diante das limitações que estão presentes no sistema. $\mathrm{O}$ relato dos entrevistados possibilita verificar as motivações para composição inicial do movimento.

[...] antes de 2009 a gente tinha em Santa Catarina [...], um movimento que chamava-se Diálogos pela responsabilidade social [...] a gente ingressou no Diálogos pela responsabilidade social, que era um grupo formado por diferentes atores da área social, mas também por empresas e por governos. O objetivo do Diálogos era debater o tema da responsabilidade social em Santa Catarina, e levar informação sobre esse tema [...] para sociedade como um todo. (ENTREVISTADO A)

A gente sentou e reunimos um grupo de gente boa, falando sobre responsabilidade social e fundamos então, criamos o Diálogos pela Responsabilidade Social. (ENTREVISTADO B)

Os entrevistados apresentam a formação inicial do movimento associada ao tema da responsabilidade social e da sustentabilidade das organizações que estavam envolvidos. Em uma das suas falas, o Entrevistado B, enfatiza que seus interesses de certo modo já buscavam outros horizontes que provavelmente se distinguiam dos caminhos apresentados pelo sistema dominante. Se pode interpretar que ao mencionar atuar "um pouco fora da caixa" (ENTREVISTADO B) seria um passo em direção oposta ao sistema hegemônico em que a sociedade estava constituída. De acordo com Touraine (2001), a composição do movimento social é caracterizada por atores que estão em uma relação de conflito com o sistema dominante, o que faz emergir interpretações que se opõem em um mesmo campo cultural. O interesse apresentado pelos entrevistados em relação ao tema, pode ser interpretado como uma manifestação de um grupo disposto a discutir um assunto e fazer a sociedade despertar sobre a importância do tema.

A gente já tem um grupo formado, a gente já tem um debate enriquecedor, mas a gente tem que fazer uma entrega maior para a sociedade, na condição que cada um tinha ali. A gente entendia que tinha um papel relevante, de potencializar as discussões, sobre temas centrais para a sociedade. (ENTREVISTADO A) 
[...] fui uma das primeiras pessoas em Santa Catarina a pesquisar sobre responsabilidade social. Na época não se falava tanto de sustentabilidade, então desde a formação na graduação eu já estudava sobre responsabilidade social. Já atuava um pouco fora da caixa em grupos sobre gestão do conhecimento, sobre movimentos diferentes [...]. (ENTREVISTADO B)

[...] a gente começou a reunir gente boa dentro do estado que estava pensando sustentabilidade, querendo pensar um pouco fora da caixa, falar sobre responsabilidade social [...]. (ENTREVISTADO B)

A formação inicial do Movimento se caracteriza então pela mobilização de pessoas de origens e com interesses distintos em torno de um mesmo um mesmo tema. Para a atuação era necessário a definição de um modelo que possibilitasse o alcance do objetivo almejado pelo grupo, ou seja, que permitisse um engajamento efetivo das pessoas envolvidas na construção do movimento. Durante as discussões sobre a forma de atuação, o grupo que estava à frente do processo teve acesso a informações sobre os Objetivos do Desenvolvimento do Milênio (ODM) promovidos pela Organização das Nações Unidas (ONU) nos âmbitos nacional e internacional. Diante dessa constatação, o grupo ampliou seus horizontes em relação ao tema a ser trabalhado.

No final de 2008, quando a gente não tinha definido o modelo de atuação do Diálogos, surgiu uma proposta de que o Diálogos pudesse tratar o tema dos Objetivos do Desenvolvimento do Milênio como o tema central do Diálogos. E foi a partir de então que surgiu o Movimento Nós Podemos Santa Catarina. A gente passou do Diálogos pela Responsabilidade Social para o Movimento Nós Podemos SC e começou a trabalhar o tema dos oito Objetivos no Estado como sendo a nossa bandeira a partir de 2009. (ENTREVISTADO A)

Assim, há uma mudança de foco da responsabilidade social corporativa para atuação com foco nos ODM. A partir dessa migração o movimento passou a possuir, segundo falas dos entrevistados, como bandeira os ODM. A indefinição em termos de um modelo de atuação possibilitou que o grupo redefinisse a sua proposta inicial e adotasse uma uma missão mais ampla:

[...] nos deparamos com os ODM no meio do processo de criação de existência dos ODM. [...] foi em 2009, se não me engano [...] migrou para os ODM. Assumimos os ODM como bandeira. (ENTREVISTADO B)

[...] o governo federal e como na época o governo federal aderiu, [... o Brasil aderiu aos ODM [...] ele (integrante do movimento Diálogos) trouxe a discussão para dentro do movimento. [...] trouxe a proximidade, a oportunidade, de tratar sobre os Objetivos do Milênio em Santa Catarina. De ser essa a bandeira do Diálogos pela Responsabilidade Social. (ENTREVISTADO A) 
A proximidade de um integrante do movimento com o governo federal possibilitou o acesso aos ODM. Esse contato inicial desencadeou as alterações no foco e na forma atuação do movimento. No que se refere a essa influência individual, é importante destacar que as falas dos entrevistados retratam a preocupação que o movimento não fosse personificado. Entretanto, pode-se inferir que os contatos e habilidades individuais eram importantes e necessários para o movimento, mas assim mesmo existia a atenção para que não houvesse uma confusão ou associação direta do movimento com determinada pessoa ou organização. O vínculo existente entre as pessoas e o movimento correspondia a uma representação de instituições e organizações através dessas pessoas.

\footnotetext{
[...] nós representávamos na época, sem personificação, pois se não tivesse eu na época a Fulana estava lá também, ou a Fulana ou outra pessoa estaria ali e teria essa cadeira dentro do Movimento. (ENTREVISTADO A)

[...] Era um grupo que de pessoas, não era de pessoas, mas de organizações representadas por pessoas que na sua grande maioria nós tínhamos nas grandes organizações, privadas, públicas [...]. (ENTREVISTADO B)
}

Ter a ciência da separação entre os interesses individuais e públicos é algo que pode ser apreendido das entrevistas realizadas. O movimento representa um coletivo que não se limita ao interesse de um ou de algumas pessoas. Mesmo considerando a centralidade dos conflitos, é importante que os atores sejam capazes de construir identidade coletivas, que além de serem novas retratem o coletivo e não sejam espaços de manipulação de interesses individuais ou de determinados grupos. Conforme apresentado por Touraine (2001), os movimentos sociais representam relações que proporcionam interações manifestadas pela ação coletiva e o sistema social. Sendo assim, ao visualizar por parte dos entrevistados a preocupação de compreender que o movimento não é uma personificação, pode-se evidenciar a preocupação em estabelecer uma identidade coletiva.

Mesmo que a migração do movimento Diálogos pela Responsabilidade Social para uma adesão aos ODM tenha ocorrido por intermédio de uma pessoa, devido seu contado com o governo federal na época, é importante destacar que o grupo tinha um pensamento de construção coletiva. Segundo os relatos das entrevistas o alinhamento do movimento Diálogos pela Responsabilidade Social com os ODM representava a adesão a um tema que estava sendo debatido e levantado internacionalmente. Os oitos ODM correspondiam aquilo que o movimento buscava ao levar para a sociedade de Santa Catarina a importância de serem trabalhadas as questões que estavam sendo levantadas mundialmente. 
[...] era uma bandeira global, o mundo inteiro estava falando sobre isso e isso do ponto de vista de estruturação era algo que já estava devidamente estruturado. Já tinha uma discussão prévia em cima disso, como o objetivo do Diálogos era levar para a sociedade discussões acerca de temas relevantes e já existia todo um debate anterior que definiu os oito objetivos. A gente entendeu que naquele momento era o tema mais adequando. Seria realmente importante a gente trabalhar os oito Objetivos em Santa Catarina, porque não existia nenhum tipo de discussão acerca dos oito Objetivos no estado. Então a gente acabou encabeçando isso e começou a trabalhar os oito Objetivos em Santa Catarina. (ENTREVISTADO A)

Destaca-se que existia uma rede prévia de relacionamento ativa de interações entre os atores, como destacado por Melucci (1996), que contribuiu para a constituição da identidade coletiva do movimento. A própria constituição inicial do movimento Diálogos pela Responsabilidade Social representava um ideal que estava sendo compartilhado pelas organizações signatárias, pois as mesmas já possuíam em suas práticas organizacionais o tema da responsabilidade social. Partindo dessa situação, conforme relado nas entrevistas, seria um movimento natural a adesão aos ODM. As organizações já possuíam uma compreensão sobre do que tratavam os temas abordados e possuíam o interesse em poder colaborar comum movimento mais amplo e internacional promovido pela ONU. Existia o entendimento que o trabalho que já estava sendo gestado pelo movimento correspondia aos princípios apresentados pelos ODM.

[..] nós já éramos pessoas que estavam colocando em prática em suas organizações esse tema da responsabilidade social. [...] como parte dessa evolução mesmo, natural de se discutir responsabilidade social e a gente tem uma bandeira internacional falando sobre os objetivos, os ODM. (ENTREVISTADO B)

Segundo as entrevistas, pelo fato dos ODM representarem uma agenda global, os oito Objetivos foram definidos a partir da visualização de problemas que estão acontecendo pelo mundo. Segundo o entrevistado A, o fato da agenda ser global e o impacto de expectativa sobre a resolução dos problemas, proporcionava um estímulo maior para abraçar a causa. Os oito Objetivos estabelecidos apresentavam uma concepção fundamentada no desafio de tornar o mundo melhor e, como mencionado pelo entrevistado A, isso se colocava como grande fator motivacional. Mesmo diante dos desafios colocados para o movimento, era importante entender o compromisso assumido e seu potencial de contribuição para o estado. 


\begin{abstract}
Era uma agenda global. Os oito objetivos foram definidos a partir de problemas no mundo inteiro. [...] mais estimulador que isso, que você sabe que [...] se a gente conseguisse minimamente alcançar aqueles objetivos, a gente teria um mundo melhor. Eu acho que não existe fator motivacional maior do que esse, apesar de todos os desafios, do ponto de vista institucional, a gente tinha um compromisso com a sociedade, mas do ponto de vista pessoal tinha um fator motivacional que era saber que aquilo era uma agenda global, que aqueles temas já tinham sido previamente discutidos e avaliados como os problemas mais latentes no mundo inteiro e que precisavam de solução. Então, como pessoa e como instituição, a gente entendia o grau de relevância daquilo para o Estado, para o país e para o mundo, e por isso, independente dos desafios, a gente continuava ali. (ENTREVISTADO A)
\end{abstract}

A existência desses desafios associados aos enfrentamentos dos problemas levantados pelos ODM pode estar associada aos conflitos sociais e aos desafios locais, que de acordo com Touraine (2001) precisam ser reinterpretados. O relato das entrevistas proporciona uma visualização inicial sobre alguns desafios enfrentados pelo grupo. $\mathrm{O}$ entrevistado A relata a importância da existência de recursos que possibilite trabalhar com os temas que são problemas complexos e de alcance global.

\begin{abstract}
Muitos desafios e um dos principais deles era recursos financeiros, porque para você trabalhar uma bandeira, como a dos ODM, você precisa ter várias frentes de atuação. A comunicação é uma delas, porque as pessoas precisam conhecer aquilo que você está falando, para elas se familiarizarem com o tema e ingressarem, começarem a fazer um trabalho em torno daquilo. Então a gente [...], era um movimento, mas precisava de recursos financeiros e recursos humanos na época principalmente, para poder fazer um trabalho mais sólido, um trabalho com mais qualidade. Então esse foi o primeiro desafio, buscar parcerias [...] para que a gente conseguisse fazer um trabalho com impacto e relevância social. (ENTREVISTADO A)
\end{abstract}

É possível perceber pelos relatos que o envolvimento de pessoas e organizações com o movimento está associado ao conhecimento e práticas pré-existentes que muitos possuiam em relação ao temas e questões dos ODM. O exercício de funções, habilidades e capacidades técnicas que estão associados ao gerenciamento e planejamento de projetos voltados a temas como a sustentabilidade, contribuiu para a adesão de membros ao movimento. A experiência que as empresas públicas, privadas e que as organizações da sociedade civil envolvidas já possuíam é algo que ajudou na formação do movimento, pois existia uma história de atuação associada ao tema trabalhado pela ação coletiva. Segundo relato do entrevistado $B$, temas como a responsabilidade social e desenvolvimento 
sustentável não são apenas explorados pelo terceiro setor, mas possuem o interesse de outras organizações, que possuiam interesse em participar e colaborar com o movimento.

A formação do movimento Diálogos pela Responsabilidade Social e seu alinhamento com os ODM é um resultado do esforço de diferentes atores sociais, que tinham uma vontade em realizar um trabalho em conjunto voltado a um interesse comum. O envolvimento direto ou indireto, de cada ator social acontecia pela sua participação em atividades de gerenciamento e eventos que eram realizados pelo próprio movimento. Cada ator social e a própria participação dos entrevistados estava associado, como destacado pelo entrevistado B, com o propósito de ajudar o movimento. Para tanto, o entrevistado B esclarece a preocupação em relação a participação dos componentes do movimento e a compreensão que se possui da prática do voluntariado.

\footnotetext{
Ensinar e ajudar as pessoas e organizações a entenderem como se faz movimento sustentável. Eu já vinha fazendo isso pela minha empresa e então assumi como voluntária a coordenação estadual de mobilização do movimento Nós Podemos, pelo período de dois anos. (ENTREVISTADO B)

A gente tem se envolvido bastante. Através da competência profissional da empresa, a gente pode ser o responsável por realizar um planejamento do movimento. O primeiro planejamento institucionalizado. Com a análise de propósito, nós fizemos um alinhamento sobre a questão de voluntariado, de mobilização de horas de voluntário. O que é ser voluntário dentro desse movimento? (ENTREVISTADO B)
}

Os desafios para o Movimento se constituíam desde a compreensão da atuação dos seus signatários até a obtenção de recursos. Mesmo diante das distintas orientações da ação coletiva, que de acordo com Melucci (1996), podem envolver solidariedade ou agregação, é necessário configurar a rede de relações sociais. Os parceiros do Movimento possuíam interesses que precisavam ser convergentes na sua atuação, desde a obtenção de recursos, até o entendimento de sua ação enquanto voluntários por exemplo. Para tanto, a constituição de parcerias e redes foi essencial.

\footnotetext{
Inicialmente os principais parceiros eram os que já estavam ali. O dinheiro vinha daquela rede que já estava ali formada, do Diálogos. Então, inicialmente os recursos vinham dali, depois a gente conseguiu uma parceria bastante interessante [...]. Acho que foi o primeiro parceiro que colocou dinheiro mesmo no movimento. Acreditou na proposta, do trabalho e também na bandeira dos ODM, porque quando você fala da área social, você tem inúmeras bandeiras. (ENTREVISTADO A)
} 
A sensibilização pela causa foi um fator de motivação para que organizações fizessem adesão ao movimento. A importância da inserção de novos membros que pudessem ajudar financeiramente o movimento era necessário para que fossem realizadas as atividades voltadas para a disseminação da importância da temática entre a sociedade. Sendo resguardada a importância de que exista uma lógica de gestão e estrutura, mas como enfatizado pelos relatos das entrevistas, o movimento não se constituía como personalidade jurídica.

[...] (parceiro) abraçou a bandeira. Ela recebeu de cima, mas ao mesmo tempo se sensibilizou e disse "não a gente pode abdicar de algum investimento em X, Y e $\mathrm{Z}$, para colocar aqui nos ODM, porque a gente acredita nisso'. Foi aí que vieram os primeiros recursos e aí sim, se estruturou-se uma organização, não era bem uma organização porque não tinha personalidade jurídica, mas tinha uma equipe, tinha um trabalho bem definido, tinha um organograma e uma governança. Então do ponto de vista de estrutura, estava organizacionalmente estruturado, só não tinha uma personalidade jurídica. (ENTREVISTA A)

Como já destacado e de acordo com o exposto por Melucci (1996), seja por agregação ou solidariedade que determine a orientação da ação coletiva, o movimento necessita de recursos que venham a contribuir com seu engajamento. A adesão do Movimento, como destacado por relatos das entrevistas, aos ODM possibilitou a obtenção desses recursos. E também seria necessário a estruturação do funcionamento do movimento, que mesmo não sendo personalidade jurídica precisava de uma organização para pôr em prática suas ações de forma a possibilitar o alcance de seus objetivos. De acordo com o entrevistado B, a partir do planejamento foram definidas algumas regras de funcionamento, que possibilitou tornar-se um movimento referência no Brasil na gestão e também no comprometimento. O fato da ação coletiva ser, conforme observado em Melucci (1996), um sistema multipolar de ações, onde estão envolvidos distintos atores, a partir de múltiplas orientações, se faz necessário a estruturação organizativa do Movimento para possibilitar uma devida interação das relações entre os atores sociais com vistas a um interesse comum.

\footnotetext{
Objetivos do Desenvolvimento do Milênio, porque não casar? Até porque isso iria dar mais folego quanto a possibilidade de captação de recurso, de realização de projetos dentro do estado de Santa Catarina, de fortalecimento. A importância de que ter um vínculo com um organismo internacional, que tivesse defendendo uma bandeira muito parecida com a nossa. Por isso então migrar no sentido de ter
} 
um fortalecimento maior de rede, de funcionamento da rede, de ter uma bandeira única, de falar em uma linguagem única. (ENTREVISTADO B)

Nos relatos surge a preocupação quanto à obtenção de recursos pelo movimento, sendo principalmente evidenciada a preocupação com o financeiro. De modo geral, a existência de recursos é algo essencial apontando pelos entrevistados para a existência e sustentabilidade da ação coletiva. Quando observado o contexto constitutivo de um movimento social, de acordo Touraine (2001), o movimento ao adotar a bandeira dos ODM e posteriormente dos ODS se envolverá com temas conflituosos e controversos já que a ação coletiva dos membros que compõem o movimento pode ir de encontro aos interesses de outros atores sociais.

As entrevistas apresentaram de forma subliminar a existência desses conflitos e a evidência de adversários que se opõem por diferentes motivos à bandeira que é levantada pelo Movimento ODS Santa Catarina. Em uma das falas da entrevistada A, ela relata que "não deu (risos), a gente buscou inúmeras vezes a parceria tanto dos governos municipais [...] mas a gente nos ODM, nunca teve um apoio efetivo, nem dos governos municipais, nem do governo estadual”. Por observação participante, mais recentemente, se constata uma aproximação do governo estadual e um distanciamento do governo federal, que demonstra ações que podem ser compreendidas como um "boicote velado" à atuação do movimento.

A vontade expressa pelo movimento pode ser deturpada por ações dos próprios membros, que diante de situações de embates políticos ou falta de compromisso podem agir de forma desfavorável à bandeira da ação coletiva. Esses membros acabam sendo "adversários internos", pois não demonstram um efetivo interesse pela bandeira ou se sentem prejudicados pelas decisões que são levadas pelo grupo. Pelos relatos das entrevistas é possível evidenciar a existência do esforço individual dos membros do movimento para promover o engajamento social dos diversos atores que fazem parte do mesmo:

\footnotetext{
A gente fez um trabalho de formiguinhas e teve várias iniciativas para levar informação. Tanto do ponto de vista da comunicação, quanto do ponto de vista de engajamento social [...] a minha avaliação é de que a gente não conseguiu alcançar a expectativa que a gente tinha de adesão da sociedade como um todo ao tema. Eu não sei se é uma característica do Brasil. Eu não sei exatamente o que é, mas as pessoas, elas se envolvem, mas não se envolvem tanto sabe. Eu me
} 
envolvo até aqui. Ah legal! Isso é bacana, mas é até aqui que eu vou, daqui para adiante eu já tenho muita coisa para fazer. (ENTREVISTADO A)

Apesar do movimento atuar numa causa de interesse geral e que mobiliza muita gente, que é a sustentabilidade, percebe-se também desinteresse e adversários que desestruturam a ação coletiva. Mesmo com essas evidências, os entrevistados relatam otimismo como observado na fala do entrevistado A: "Eu acredito no formato de trabalho. Eu acredito na bandeira. Eu acredito que se a gente tem uma ampla discussão sobre temas e consegue chegar no consenso que os dezessete temas são os mais relevantes para o mundo". O entrevistado B destaca: "participar desse movimento traz aderência, de dizer 'opa eu me identifico com essas pessoas que estão querendo fazer desse jeito"”.

A ação coletiva por mudança e a crença positiva no movimento, também está presente no relato do entrevistado B que: “o que motiva não mudou, desde os Diálogos pela Responsabilidade Social até hoje é estar entre estas pessoas que estão pensando de modo inovador, que querem fazer um mundo melhor". Tam compreensão é é corroborada pelo entrevistado A ao explicar suas motivações para abraçar a causa, ao relatar que: "um movimento que envolve diferentes temas que são relevantes para a sociedade e que podem fazer com que a gente tenha uma sociedade mais justa, mais igualitária e enfim uma sociedade melhor". Essas falas ajudam a compreender os fatores que contribuem e influenciam para a ação coletiva a partir dos interesses expostos pela vinculação ao movimento ODS Santa Catarina.

\section{CONSIDERAÇÕES FINAIS}

A realização desse estudo proporcionou um olhar sobre a questão da ação coletiva, sua emergência, estruturação e desafios, a partir da lente teórica dos NMS. O estudo de caso realizado sobre o Movimento ODS Santa Catarina permitiu identificar como emerge e se configura a identidade coletiva de um NMS. A investigação empreendida por meio de observação participante, entrevistas e análise documental possibilitou compreender a prática, a forma e as motivações que definem o movimento. Através das memórias apresentadas pelo relato dos entrevistados foi possível entender que a ação desempenhada pelos atores sociais está associada as habilidades e capacidades pessoais e profissionais relacionadas aos temas da responsabilidade socioambiental corporativa e desenvolvimento 
sustentável. As motivações para a participação dos membros do movimento estão ligadas à vontade de contribuir com astransformações necessárias para o desenvolvimento sustentável, sendo o foco de atuação o estado de Santa Catarina. A prática relacionada à ação coletiva representa um conjunto de motivações que moldam o movimento para o alcance do seu objetivo.

A trajetória constitutiva do movimento está associada à realidade brasileira e mais especificamente ao estado de Santa Catarina. A bandeira defendida pelo movimento representa uma busca por melhoria da qualidade da vida e entende que a luta deve ser estabelecida por meio de uma ação conjunta de diferentes atores e setores da sociedade, com ênfase nas instituições, tendo o setor corporativo o papel de protagonista

A realidade constitutiva do movimento se depara com essa complexidade desde sua concepção, enquanto ação coletiva, que se amplia diante dos desafios enfrentados cotidianamente. A adesão do movimento aos ODS representa uma convergência com as ações desenvolvidas que possuiam relação aos dezessete objetivos propostos mundialmente. A identidade coletiva passa então a estar representada em torno da temática do desenvolvimento sustentável que faz convergir o repertório dos atores sociais que são signatários ao movimento. As ações do grupo são norteadas por esta identidade coletiva e as estratégias estabelecidas estão voltadas para a disseminação, compreensão e envolvimento da sociedade com a importância do desenvolvimento sustentável no âmbito do estado.

Conforme o relato dos entrevistados é perceptível que o movimento vem promovendo uma transformação cultural. Tal transformação está associada ao esforço individual dos membros do movimento para promover o engajamento social no estado em torno dos ODS. Para tanto, tem sido essencial uma comunicação eficiente com a publicização do tema, através das campanhas realizadas pelo movimento para transmitir a mensagem do significado dos ODS. Por isso, a importância destacada pela observação participante e pelos membros entrevistados da mudança total do modus operandi do movimento na transição dos ODM para os ODS. Isso permitiu alinhar determinadas prioridades que os integrantes possuíam, com o sentido de unificação das mesmas aos objetivos do movimento. Para tanto, foi importante a crença e a adesão à bandeira levantada pelos ODS para o enfrentamento e superação dos desafios, que vão desde a necessidade de recursos financeiros até o comprometimento de seus integrantes em prol da causa. 
A experiência na área de sustentabilidade e responsabilidade social que os integrantes do movimento possuíam, também ajudou muito na constituição do movimento. Pois, dessa forma, foi possível construir um "pensar fora da caixa" e gerar uma transformação cultural que questiona os sistemas sociais hegemônicos. O movimento tornase forte quando existe compromisso com as pessoas ao lutar por temas que não possuíam espaço para o debate e reflexão, o que tem aberto espaço para ações inovadores. Entretanto destaca-se também que o movimento encontra resistências e "inimigos" que pouco se engajam ou ainda boicotam suas ações e campanhas, as quais muitas vezes vão de encontro a interesses dominantes.

A trajetória de constituição do Movimento ODS-SC, iniciada a partir do Grupo Diálogos pela Responsabilidade Social coloca-se assim como um importante passo para a compreensão da importância de ser trabalhado uma bandeira que representa uma agenda global no estado. Uma bandeira baseada em problemas do mundo todo e concebida a partir da sustentabilidade e suas dimensões econômico, ambiental e social. Diante disso, o estudo aqui em tela permite visualizar as particularidades e dificuldades de constituição e desenvolvimento dos NMS e como esses podem ser vetores de apropriação de repertórios amplos e globais, fazendo acontecer, a partir de suas lutas e práticas cotidianas, transformações sociais, culturais, políticas e ambientais em âmbito local.

\section{REFERÊNCIAS}

ABERS, R.; BULOW, M. V.. Movimentos sociais na teoria e na prática: como estudar o ativismo através da fronteira entre Estado e sociedade? Sociologias, Porto Alegre, ano 13, no 28 , set./dez. 2011.

ALONSO, A. As teoriais dos movimentos sociais: um balanço do debate. Lua Nova, São Paulo, 76: 49-86, 2009.

ALVAREZ, A. R.; MOTA, J. A. (Orgs). Sustentabilidade ambiental no Brasil: biodiversidade, economia e bem-estar humano. Brasília: IPEA, 2010. 640 p. Disponível em:

<http://www.ipea.gov.br/agencia/images/stories/PDFs/livros/livros/livro07_sustentabilidad eambienta.pdf>. Acesso em: 20 jan. 2020.

BRASIL. Secretaria Nacional de Relações Político Sociais. Rev. do Prêmio Objetivos de Desenvolvimento do Milênio, 5 ed.. Brasília: Presidência da República, 2015. Disponível em: < http://www.odmbrasil.gov.br/arquivos/revista-da-5o-edicao>. Acesso em: 20 jan. 2020. 
CALHOUN, C.. New Social Movements of the Early Nineteenth Century. Social Science History, V. 17, N. 3, 1993.

COHEN, D. ; ARATO, A. The New Social Mouvements Paradigm In: COHEN, D. \& ARATO, A. Civil Society and Political Theory. Massachussets : MIT Press, 1994.

COHEN, J. L.; ARATO, A. Civil Society and Political Theory. Cambridge: MIT Press, 1992.

GOHN, M. da G.. Teoria dos Movimentos Sociais: paradigmas clássicos e contemporâneos. São Paulo: Edições Loyola, 2006.

LACLAU, E. Os novos movimentos sociais e a pluralidade social. Revista Brasileira de Ciências Sociais, São Paulo, v. 1, n. 2, p. 41-47, out. 1986.

MELUCCI, A.. Um objetivo para os movimentos sociais? Lua Nova, São Paulo, 16: 49-66, 1989.

MELUCCI, A.. The construction of collective action. In: Challenging Codes. Collective Action in the Information Age. Cambridge: Cambridge University Press, 1996.

NUNES, Cristina. O conceito de movimento social em debate. Sociologia, Problemas e Práticas, n. 75, 2014.

ONU. Organização das Nações Unidas. Declaração do Milênio. Nova York, set. 2000. Disponível em <https://www.br.undp.org/content/brazil/pt/home/library/ods/declaracao-domilenio.html>. Acesso em 20 jan. 2020.

ONU. Organização das Nações Unidas. Transformando nosso mundo: a agenda 2030 para o desenvolvimento sustentável. Nova York, set. 2015. Disponível em <https://nacoesunidas.org/wp-content/uploads/2015/10/agenda2030-pt-br.pdf >. Acesso em 20 jan. 2020.

TOURAINE, A.. O retorno do ator. Lisboa: Instituto Piaget, 2001. 